\title{
VI.-DISCUSSIONS.
}

\section{ETHICS FROM A PURELY PRACTICAL STANDPOINT.}

I Have read Mrs. Bain's interesting article on the above title in the July number of MiND. As she refers to some of my statements in illustration of the unpractical character of Neo-Kantian or Idealistic Ethics perhaps I may be permitted one or two words of explanation. It seems a pity that Utilitarians like Mrs. Bain should unwittingly misrepresent the Idealistic view. With all due allowance for the alleged obsourity of the writers who support it I cannot help thinking that if the opponents of that view had taken half as much trouble to understand it as its champions have taken to understand Utilitarianism this would not have been so. It seems especially a pity in a discussion of this kind, which is nothing if not serious, to insinuate any want of sincerity on either side. I do not know for instance why it should be hinted ss it seems to be on p. 334 that Mr. Spencer is superior to Idealistic writers in not "pandering to received views". I should have thought that a theory such as that of the Neo-Kantians, expressly disowning as it does all appeal to merely selfish interests, is much more opposed to the frankly egoistic basis of much of the popular and even religious teaching of the present time than Mr. Spencer's, which is at best a compromise between egoism and altruism. Passing over this and speaking for myself alone, I shall state the issue raised by $M r s$. Bain as it presents itself to me, and my reason for suspecting the claims of current Hedonism to be a good working theory in ordinary practice.

Both Idealists and Utilitarians appeal to consequences as a test of conduct. It seems odd that Mrs. Bain should speak throughout as though the appeal to consequences were a monopoly of Utilitarians. Idealists have always emphasised the point that conduct takes effect in a world of concrete interests, and that its value must be tested by its tendency to further the supreme interest of human life, whatever that may be. They differ from Utilitarians in their way of conceiving of this supreme interest. Utilitarians say it is the greatest amount of pleasure; Idealists say it is the development of a system of activities which depend for their value not on the amount of agreeable consciousness with which they are accompanied, but on their harmony with an ideal of human life. It is 
well to state these theories in terms of "pleasure " and "system" respectively, and to avoid such question-begging terms as "happiness," "well-being" and "welfare" which are used by both indifferently. Mrs. Bain is apparently unaware of this ambiguity and uses "well-being" as though it were clearly synonymous with greatest plessure.

The question that Mrs. Bain proposes is, Which of these theories is the more effective, first as a guide, second as a motive, to desirable conduct?

To the Utilitarian the interest of her paper will consist not as she seems to suppose in the originality of her question but in the heresy of her answer. J. S. Mill as everybody knows was led by his personal experience to maintain that from the point of view of individual happiness it was not desirable to cultivate the habit of considering conduct from the hedonistic point of view. The best practical results were in his opinion to be obtained by avoiding the use of the plessure calculus, and pursuing objective interests as though they had a value on their own account. Mr. Spencer may be said to have extended this " paradox of Hedonism " to the sphere of politics and an altruistic conduct in general. He tries to show that here also the best results are obtained by setting before ourselves and others not the production of happiness as the immediate object, but the maintenance of the conditions of life. Professor Sidgwick to this extent agrees with both that he is never tired of emphasising the difficulties that beset the attempt to form a direct estimate of plessures and pains, and the undesirability of relying on a purely utilitarian morality. Undeterred by these authorities Mrs. Bain proposes to revert to the claim of primitive Utilitarianism that "grestest plessure" is not only an accurate guide but an effective motive to desirable conduct.

Leaving Utilitarians to settle this difference among themselves, the critic of Utilitarianism will find in Mrs. Bain's contention a welcome simplification of the issue. In discussing the practical difficulties of the theory as a guide to conduct and a basis of appeal he has hitherto felt himself handicapped by the admissions of its own supporters. Whatever he said on the difficulties of striking a balance of pains and pleasures the Utilitarian himself was always prepared to go one better in the same direction. And when he pointed to the ineffectiveness of the appeal to self-interest or others' happiness, he was met by the rejoinder that Utilitarians don't appeal to them. But here he will feel is a plain issue. Is the theory as unworkable in practice as he holds it to be untenable in theory? To further simplify the question we may here leave out all reference to the difficulties that beset the attempt to estimate hedonic consequences with any degree of accuracy. I doubt very much whether any one who has realised the force of the considerations put forwand by Professor Sidgwick and others will find in the few sentences Mrs. Bain devotes to this subject an adequate reply to them. 
Confining myself to the question of "effectiveness" I shall state as shortly as I can the objections which seem to me decisive against Mrs. Bain's contention.

1. This theory sets the pleasure of the individual in competition with general well-being. To lose sight of his own greatest happiness (granting that it is possible at all) is as immoral as to lose sight of the greatest happiness of others. He seems even to be bound to give it prior consideration: "We must work," says Mrs. Bain, following Mr. Spencer, "first for ourselves then for others". Yet short of the millennium Mr. Spencer foreshadows, when the lion of egoism will lie down with the lamb of altruism, what guarantee have we that these two will coincide? In the conduct demanded by the higher morality of any time with which we are likely to have any practical acquaintance, are they not almost certain at one point or another to collide? And in these circumstances with what degree of effectiveness can appeal be made to the waverer? The reader may judge for himself of the power of an appeal to altruistic conduct which on the pain of insincerity and hypocrisy must be crossed by a reminder of the danger which threatens individual happiness.

2. It is only stating the same objection from another point of view to note that Hedonism sets the lower instincts in competition with the higher. In all estimates the pleasure that comes from following the lower must by the consistent hedonist be set against that which comes from the higher. And it is inevitable in the present stage of human development that to the great mass of man. kind the latter should seem distant, problematic and insipid in comparison with the former.

These points are of course only the practical side of the theoretical objections that have been urged from all time against Hedonism. It has frequently been pointed out that the task of proving that the happiness of the individual and the happiness of society as esti. mated in terms of pleasure necessarily coincide is a hopeless one. It is in Ethics, as Mr. Leslie Stephen says, what the attempt to square the circle is in Mathematics. Similarly from the side of the individual and his instincts it is of course impossible to show in every case that to follow the higher will produce greater pleasure. It was to meet this difficulty that Mill introduced his celebrated distinction of quality in pleasures. "This conduct," he would say, "cannot be shown to produce more pleasure than that, but it is higher." We all know the passage in Utilitarianism. It is magnificent, but it is not Hedonism.

Whatever difficulties stand in the way of the attempt to make Idealism edifying, and of course they are legion, as any one who has ever made the rash attempt is likely to have discovered, it at any rate escapes those that I have pointed out as fatal to Hedonism. In the first place it proposes a definition of social good which reconciles instead of merely compromising between the clsims of self and others. And in the second place it takes individual well-being to 
consist not in a succession of agreeable feelings valued in proportion to their total amount irrespective of their source but in a certsin quality of life. These contentions justify the moralist in appealing on the one hand to a larger or social self against the narrower and unsocial, and on the other hand to a higher life as against a lower. If asked to define what he means by the social self and the higher life the Idealist will have his work cut out for him. If the answer he elaborates is a little vague who can blame him? Aristotle warns us against expecting the same kind of exactitude in Ethics as we have in Mathematics. So does Mrs. Bain. And if there is any part of Ethics in which want of accuracy is more excusable than in another it is in sketching the outlines of the moral ideal. But all this only means that the acquirements of an ethical priesthood (in the necessity of which it is interesting to notice that Mrs. Bain along with Mr. Spencer and the Positivists believes) must go deeper than a mere familiarity with the formula of primitive Utilitarianism and a turn for the arithmetic of pleasure. They must include among other things at least some sympathy with the best ideals of human character and some insight into the general trend of social progress.

J. H. Muirhead. 